Received Date : 07-Sep-2015

Revised Date : 29-Mar-2016

Accepted Date : 30-Mar-2016

Article type: Paper (under 8000 words)

$\square$

\title{
Brain Bases of Morphological Processing in Chinese-English Bilingual Children
}

Ka I Ip ${ }^{1}$, Lucy Shih-Ju Hsu ${ }^{3}$, Maria M. Arredondo ${ }^{1}$, Twila Tardif ${ }^{1,2}$, Ioulia Kovelman ${ }^{1,2^{*}}$

${ }^{1}$ Department of Psychology, University of Michigan, 530 Church Street, Ann Arbor MI, 48109

${ }^{2}$ Center for Human Growth and Development, University of Michigan, 300 North Ingalls, Ann Arbor MI, 48109

${ }^{3}$ Department of Psychology, University of Hong Kong, Centennial Campus, Pokfulam Road, Hong Kong

*Corresponding Author: Ioulia Kovelman, kovelman@ umich.edu, Phone: 734.647.3712

Research Highlights:

- Cross-linguistically, words are comprised of sounds (phonemes) and meanings (morphemes). Nonetheless, there is also significant variability in how meanings are related to sounds across

This is the author manuscript accepted for publication and has undergone full peer review but has not been through the copyediting, typesetting, pagination and proofreading process, which may lead to differences between this version and the Version of Record. Please cite this article as doi: $\underline{10.1111 / \text { desc. } 12449}$

This article is protected by copyright. All rights reserved 
languages. The present study reveals the brain bases of how young Chinese-English bilinguals relate sounds to meanings in each of their languages.

- Young Chinese-English bilinguals with early and systematic exposure to each of their languages showed native-like competence and language-specific neural organization for morphological awareness abilities in each of their languages.

- Chinese-English bilinguals had greater activation than English monolinguals in the left MTG region for the English language tasks, suggesting that bilingual exposure to a language with greater emphasis on meaning-to-print associations impacts the functionality of this region.

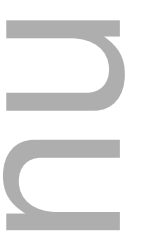

\section{Graphic Abstract}

The study investigated the impact of bilingual exposure on children's language and reading abilities. During auditory morphological awareness tasks, young Chinese-English bilinguals showed monolingual-like competence as well as language-specific patterns of brain activation in left inferior frontal gyrus (IFG). This activation was greater for English than for Chinese in left IFG BA 45, but similar across languages in left IFG BA 47. Relative to English monolinguals, the bilinguals showed greater activation in left MTG region and this activation was significantly correlated with bilinguals' English literacy. The findings suggest that bilingual exposure to a language with rich lexical morphology, such as Chinese, impacts the functionality of bilinguals' left temporal regions typically associated with lexicosemantic processing and the ability to link word meanings to their orthographic forms.

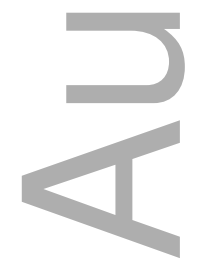



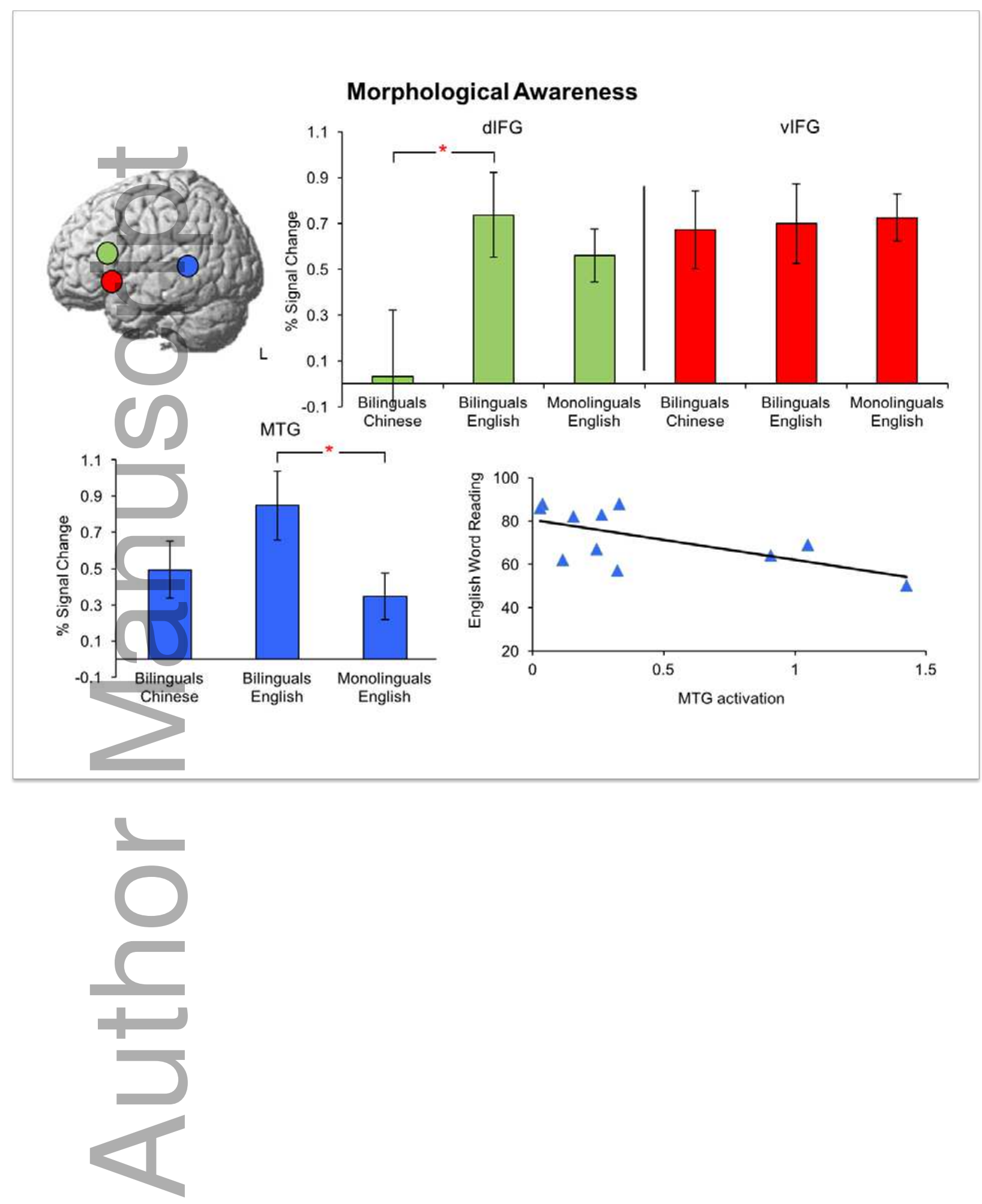

This article is protected by copyright. All rights reserved 


\begin{abstract}
Can bilingual exposure impact children's neural circuitry for learning to read? To answer this question, we investigated the brain bases of morphological awareness, one of the key spoken language abilities for learning to read in English and Chinese. Bilingual Chinese-English and monolingual English children $(\mathrm{N}=22$, ages 7-12) completed morphological tasks that best characterize each of their languages: compound morphology in Chinese (e.g., basket+ball = basketball) and derivational morphology in English (e.g., re+ do = redo). In contrast to monolinguals, bilinguals showed greater activation in the left middle temporal region, suggesting that bilingual exposure to Chinese impacts the functionality of brain regions supporting semantic abilities. Similar to monolinguals, bilinguals showed greater activation in the left inferior frontal region [BA 45] in English than Chinese, suggesting that young bilinguals form language-specific neural representations. The findings offer new insights to inform bilingual and cross-linguistic models of language and literacy acquisition.
\end{abstract}

Keywords: bilingual, morphological awareness, phonological awareness, reading acquisition

\title{
Brain Bases of Morphological Processing for Learning to Read in Chinese-English Bilingual Children
}

Theories of bilingualism suggest that proficient bilinguals form common cognitive and neural bases to support word knowledge in both of their languages (Hernandez \& Li, 2007; Kroll, 2015). These common bases should allow bilingual children to share or "transfer" language abilities to support emergent reading abilities (Cummins, 2001). In practice, there is substantial variability in how speakers of different languages map linguistic units onto print (Seidenberg, 2011), which may in turn limit bilinguals' ability to transfer their emergent literacy skills across the two languages (Bialystok, 2013). For instance, researchers find that monolingual speakers of Chinese and English differ in both the analytical strategies (Perfetti, Liu, \& Tan, 2005) and brain activation patterns (Tan, Laird, Li, \& Fox, 2005) that they activate during word reading tasks. Yet, it remains unclear if the observed differences are specific to orthography or also reflect underlying spoken language differences between the two languages (Nakamura et al., 2012). Although most words are comprised of units of sound and meaning, there is significant 
variation in how sounds interact with meanings within a lexical structure (Perfetti et al., 2005; Seidenberg, 2011). These differences, in turn, interact with children's learning to read (McBrideChang et al., 2013). Here we ask how such cross-linguistic variation may affect word processing and learning to read in young bilingual learners of English and Chinese as compared to monolingual English speakers.

Acquisition of natural human languages typically precedes and predicts learning to read (Ziegler \& Goswami, 2005). Spoken words are comprised of sounds (phonemes) and units of grammar that carry meaning (morphemes). Until recently, much focus has been on the role of phonology and phonological awareness, its brain bases across languages, and the transfer of this ability for learning to read in young bilingual children (Bialystok, 2013; Hammer et al., 2014). Yet, newly emerging theories suggest that children's sensitivity to the morphological structure of spoken words is also a foundational skill for achieving reading mastery across languages and orthographies. Understanding the brain bases of morphological awareness, its relevance for learning to read, and the impact of bilingual exposure on this ability will help us shed new light on neural mechanisms that support learning to read across bilingual as well as monolingual speakers of different languages.

In Chinese, morphological awareness is especially important for learning to read. Many Chinese words are comprised of two or more syllables; and, in Chinese, these syllables are often also meaningful morphemes. For instance, in Chinese, the word “篮球 (basketball)” is a morphologically compound word with two syllables (i.e.「篮」"basket” $+\lceil$ 球」"ball”) that are also meaningful root morphemes (Liu et al., 2010). Similarly, the word “火车(train)” is comprised of two meaningful morphemes 「火」 "fire" and 「车」 "vehicle" that make the word “火车” (fire-vehicle = train). This is unlike Indo-European languages, such as English, in which syllables can be either meaningful morphemes or meaningless units of sound (-er is a morpheme in the word play-er, but is a meaningless syllable in the word flower). This feature of spoken Chinese is also reflected in Chinese orthography, which includes direct character-to-morpheme mappings (Siok \& Fletcher, 2001). For example, adding the characters 「氣」 “air” $+\lceil$ 泡」 “bubbles” makes the word 「氣泡」“air bubbles," while adding the characters「水」"water”+ 「泡」“bubbles” makes the word「水泡」”water-bubbles,” which means “blisters.” Not surprisingly, this salient morphological feature of Chinese language has been found to play a 
significant role in children's literacy (c.f., McBride, 2015). More specifically, in Chinese, morphological awareness, as tested in the spoken language modality in preschool age children, has been shown to precede and predict literacy success and dyslexia in early grades (McBrideChang et al., 2011).

Indo-European languages like English also have morphological patterns embedded into words in the form of morphological compounding (e.g., baseball, basketball). Yet a more defining feature of their lexical morphology is derivational, which means adding derivational prefixes (e.g., un-) and/or suffixes (e.g., -ness) to root (e.g., kind) morphemes to make words like unkind or kindness. As tested in spoken language, English morphological awareness, has been found to make a small but significant contribution to reading ability in the early grades, after controlling for phonological awareness, vocabulary, IQ, and other factors (e.g., Apel, Diehm, \& Apel, 2013). This is likely because English offers relatively low sound-to-print predictability and requires its readers to understand associations between morpho-syllabic units and print (e.g., to distinguish words like for and four, Ehri, 2014) and because derivational morphology taps into both the meaning and grammatical representations of languages (Deacon, 2012).

Although morphological awareness is important for achieving reading mastery across such typologically distinct languages as English and Chinese (Carlisle \& Goodwin, 2013; McBride-Chang et al., 2005), the structural linguistic differences may preclude effective transfer of this ability between bilinguals' two languages. For instance, researchers have found that bilinguals' awareness of compound morphology can transfer bi-directionally to support literacy in both English and Chinese languages. In particular, models predicting bilingual literacy show that children's compound awareness in one language makes a significant contribution to their literacy acquisition in another language (Wang, Lin, \& Yang, 2014; Zhang, McBride-Chang, Wagner, \& Chan, 2014). Yet, this does not seem to be the case for derivational morphology (Zhang et al., 2014); researchers have found that Chinese-English bilinguals might have lower derivational morphology skills than English monolinguals or even Spanish-English bilinguals, likely because the derivational morphology structure of English is more similar to Spanish than Chinese (Ramirez, Chen, Geva, \& Luo, 2011). It is therefore possible that to become successful at reading in each of their languages, young Chinese-English bilinguals must form languagespecific cognitive representations for the morphological regularities that best characterize each of their respective languages. 
What might the language-specific and shared neural bases for morphological awareness in Chinese-English bilinguals be? In sharp contrast to phonological awareness, very little is known about the brain bases of morphological awareness in either English or Chinese. This is an important gap considering the morpho-syllabic nature of successful word reading in both languages (Ehri, 2014; McBride-Chang et al., 2005). To the best of our knowledge, only two prior studies have examined the brain bases of morphological awareness in monolingual Chinese children. The fMRI study by Liu et al. (2013) revealed that typically-developing readers showed differential activation in left middle frontal gyrus (MFG Brodmann Area [BA] 9) and left ventral inferior frontal regions (IFG BA 47) when making semantic judgments about printed word pairs that varied in their morphological processing demands; this effect was reduced in children with dyslexia (Liu et al., 2013). An ERP study by Tong et al. (2014) also revealed a robust N400 response during a morphological awareness task, whereas the same N400 response was diminished in children with dyslexia. Left MTG is thought to be one of the key regions that generate the $\mathrm{N} 400$ response during lexico-semantic processing (Friederici, 2012). It is therefore likely that left MFG, ventral IFG and MTG regions, regions typically associated with lexicosemantic processing, support morphological awareness in Chinese-speaking children.

This finding of left MFG (BA 9) and IFG (BA 47) activation during morphological processing in Chinese is generally consistent with the neuroimaging research on literacy and reading acquisition in Chinese (Cao et al., 2010, 2011; Siok, Niu, Jin, Perfetti, \& Tan, 2008; Siok, Perfetti, Jin, \& Tan, 2004). Researchers often find that during word reading, Chinese readers, relative to English readers, often show greater activation in left ventral IFG BA 45/47 regions typically associated with lexico-semantic analyses (Bozic, Tyler, Su, Wingfield, \& Marslen-Wilson, 2013). In contrast, English speakers show greater activation in left dorsal IFG BA 45/44 regions typically associated with phonological and syntactic analyses (Friederici \& Gierhan, 2013). While the cross-linguistic differences are often interpreted in terms of the orthographic complexity of Chinese relative to English (especially the mapping of sound to print), it remains possible that these differences also reflect the language-specific characteristics of underlying morphological word processing. To explore this hypothesis, we compared children's brain activation during morphological awareness tasks between young ChineseEnglish bilinguals and English monolinguals and between English and Chinese languages in bilingual speakers of the two languages. 
Morphological awareness emerges before a child learns to read and interacts with children's subsequent reading experiences across English and Chinese (Deacon, 2012; McBrideChang et al., 2013). Knowing the shared and overlapping neural correlates of bilinguals' two languages for morphological processing may therefore help us better understand the extent and the limitations of bilingual language "transfer" ability as well as the mechanisms by which young bilinguals organize spoken language abilities that are key for achieving reading mastery in each of their languages (Bialystok, Luk, \& Kwan, 2005; Ramirez et al., 2011; Zhang et al., 2014). Thus, in the present study we asked young bilingual Chinese-English children and English monolinguals to complete tasks of auditory morphological awareness and a control wordmatching task during fMRI neuroimaging.

Hypotheses and Predictions. The overarching goal of this study was to investigate whether structural and orthographic characteristics of the languages that bilingual-speaking children are learning can impact their literacy and neural architecture for learning to read. To do this, we considered two separate hypotheses - the bilingual transfer and language-specific development hypotheses. On the one hand, we hypothesized that bilingual exposure to Chinese, a language that places great emphasis on lexical morphology to process words in speech and print (Perfetti et al., 2005), would result in bilingual transfer and impact children's literacy as well as the neural organization for lexico-semantic processing. From this hypothesis comes a number of more specific predictions about literacy development and the brain bases underlying literacy in each of the child's languages.

With respect to literacy development, we predicted that, when reading and performing tasks in English, bilingual Chinese-English children would show stronger associations between their lexico-semantic and word reading abilities than English monolinguals. We tested this prediction with correlational as well as regression analyses. Second, we predicted that during a morphological awareness task in English, bilingual children would show greater activation in left MTG region and stronger associations between left MTG activation and learning to read than monolinguals. This prediction is based on prior findings suggesting that better readers of Chinese showed a stronger N400 component than children with dyslexia (Tong et al., 2014), while left MTG is thought to be one of the key regions that generate the N400 response during lexicosemantic processing (Friederici, 2012). Finally, we predicted better readers would have lower activation in left MTG region because a recent meta-analysis suggests that older and better 
readers show reduced activation in left posterior temporal regions, which might be an index of improved language and reading automaticity (Martin et al., 2015).

On the other hand, we also hypothesized that early and systematic dual language exposure should yield language-specific development for each of the children's languages. This hypothesis also led to literacy and brain function predictions. First, we predicted that ChineseEnglish bilinguals would show stronger associations between morphological and word reading abilities in Chinese than in English. We tested this prediction with correlational as well as regression analyses. Second, we predicted that during morphological awareness tasks in each of their languages, bilinguals would show greater activation in left ventral IFG in Chinese and greater activation in left dorsal IFG in English. This prediction is based on prior neuroimaging research suggesting that while both Chinese and English readers show activation in meaningassociated (ventral IFG) and phonology-associated (dorsal IFG) brain regions, the relative strength of activation in these regions during similar tasks might differ between English and Chinese (Tan et al., 2005).

To test these hypotheses, we asked bilingual Chinese-English and monolingual English children to complete standardized and/or previously published measures of single-word reading, lexico-semantic processing (morphological awareness and vocabulary) as well as phonological awareness tasks. The participants also completed auditory lexical morphology tasks in each of their languages during fMRI scanning. The children completed a derivational morphology task in English (based on Carlisle, 2000), and a compound morphology task in Chinese (based on McBride-Chang, Shu, Zhou, Wat, \& Wagner, 2003). They also completed a word matching control condition that required lexical access without additional morphological manipulation (e.g., the words kitten-kitten match and table-chair do not match). All morphological awareness tasks (in-scanner and additional behavioral tasks) were administered only in the auditory/spoken language modality to ensure that the participants' performance on those tasks was not affected by their orthographic skills. This is also the modality in which these abilities first emerge, preceding and predicting learning to read. In sum, the goal of this study was to investigate the impact of bilingual exposure on learning to read so as to inform theories of bilingual acquisition and to challenge more general theories explaining literacy across orthographies and learners.

Method

\section{Participants}


Bilingual participants. A total of 57 (39 girls, 18 boys; mean $\left[\mathrm{M}_{\text {age }}\right]=8.71$ years; $\mathrm{SD}=$ 1.74 ; range $=6.37-12.72$ years; average grade $=3^{\text {rd }}$ grade) bilingual children participated in a larger study of bilingual Chinese-English literacy (Hsu, Ip, Arredondo, Tardif \& Kovelman, under review). Right-handed children with no metal implants were invited to participant in the neuroimaging part of the study. Unfortunately, only 14 children agreed to undergo fMRI scanning, of which only 11 were included in the final analyses ( 6 females; $M_{\text {age }}=9.58$ years, SD $=1.39$; range $=8.05-11.73$ years) due to fMRI data motion artifacts (see imaging sections below).

The bilinguals received exposure to Mandarin Chinese from birth, and at least one of the children's parents was a native speaker of Mandarin Chinese, born and raised in a Chinesespeaking country. All bilinguals' parents reported consistent use of Mandarin Chinese with their child(ren). All bilinguals started systematic exposure to English by age four (as measured by time of English daycare entry), and had at least 4 years of bilingual exposure prior to testing. All bilinguals received Mandarin Chinese literacy instruction at home and/or in after-school programs. The bilingual participant selection criteria included Chinese and English vocabulary knowledge. In Chinese, the children completed Chinese Picture Identification receptive vocabulary task (originally created in Cantonese and adapted for Mandarin; Cheung, Lee \& Lee, 1997; Newman, Tardif, Huang, \& Shu, 2011). The task does not have a standard score and we therefore required the children to have a minimum of $65 \%$ accuracy from the total of 64 items. In English, the children completed a standardized receptive vocabulary test that was part of the Kaufman Brief Intelligence Test of Verbal Knowledge assessment (KBIT-2; Kaufman \& Kaufman, 2004) and we required the children to have a minimum standard score of 85 in English to be included in the study.

Monolingual participants. A total of 77 (36 girls, 41 boys; $\left[\mathrm{M}_{\mathrm{age}}\right]=9.24$ years; $\mathrm{SD}=$ 1.82 ; range $=6.05-13.01$ years; average grade $=3^{\text {rd }}$ grade $)$ monolingual English children participated in the larger study (Hsu et al., under review). A sample of seventeen right-handed monolingual children without a history of neurodevelopmental impairments completed an fMRI session (detailed results published in Arredondo et al. (2015)). For the present investigation we selected data from eleven monolinguals who were age- and gender-matched to the final bilingual sample (6 females; $\mathrm{M}_{\text {age }}=9.67, \mathrm{SD}=1.50$; range $7.58-12.51$ ) so as to maximally match the bilingual group and to maintain the same statistical threshold across the two groups (Table 1). 
The study was advertised throughout the community in southeast Michigan. All participants were recruited from the same neighborhoods and school districts. Participants were typically developing right-handed children with no history of cognitive, motor, language, hearing or reading difficulties or delays; no brain injury, no current regimen of medication affecting brain functioning. All children were attending regular English-only schools starting age 5. The institutional review boards for research with human participants approved the study; parents and children completed informed consent/assent forms and were monetarily compensated for their time.

\section{Measures and Procedure}

All participants completed standardized behavioral assessments of language and literacy in English, and comparable published experimental measures of these cognitive constructs in Chinese for bilinguals. These included single-word reading tests in English (Word ID subtest, Woodcock Reading Mastery Tests Revised [WRMT-R]; Woodcock, 1998) and Chinese (Shu, Peng, \& McBride-Chang, 2008). The participants completed a standardized measure of phonological awareness in English (Elision subtest, Comprehensive Test of Phonological Processing [CTOPP]; Wagner, Torgesen, \& Rashotte, 1999) and an experimental phonological awareness measure that was comparable to the English task in Chinese (Newman, Tardif, Huang, \& Shu, 2011). During the Elision phonological awareness task in English and in Chinese, children heard a word and were asked to repeat this word without one of its phonological units (e.g., say "cat" without the "k" - correct answer "at"). The participants also completed published experimental measures of derivational morphology in English (Carlisle, 2000), and compound morphology in Chinese (McBride-Chang et al., 2003). During the English morphological awareness task, children heard a word (e.g., help) and then a sentence with a missing word within the sentence (e.g., Mother says I'm a good____ ). The children's task was to complete the sentence with the support of the target word (e.g., Mother says I'm a good helper). In Chinese children would hear an example sentence (e.g., Trees that grow apples are called apple+trees.), followed by a target question to elicit a compound word (e.g., How would you call a tree that grows bread? - correct answer "bread+tree"). The bilinguals completed two visits, one for English and one for Chinese behavioral testing. Only native speakers of each of the children's languages administered behavioral testing, neuroimaging practice and task reminders during fMRI scanning. Specifically, monolingual native speakers of English and 
bilingual native speakers of Chinese were present during all neuroimaging sessions with bilinguals, with tasks being administered by the native speakers in the native language for the language being tested. Those who participated in fMRI scanning also completed a mock scanner visit. See Table 1 for children's performance on all tasks. Behavioral testing preceded fMRI testing.

\section{Imaging Measures: fMRI participants}

Children who partook in the fMRI session completed a morphological awareness task in English and another in Chinese during brain scanning. Each task was $~ 7$-minutes block-designed that included an experimental morphological awareness condition, a control word-matching condition, and rest periods. During the resting baseline, participants were asked to look at a $24 \mathrm{~s}-$ fixation cross in the middle of the screen. In all experimental tasks and conditions, there was a total of 6 blocks for each condition (including fixation/rest), there were four 6 s trials per block (24 trials with an equal number of "yes" and "no" randomized answers), in which two words were played within the first $4 \mathrm{~s}$ (average word duration: English word $=678 \mathrm{~ms}$; Chinese word $=$ $894 \mathrm{~ms}$ ), followed by a 2 s question mark. Participants received an audio and visual prompt indicating whether the upcoming condition was a "word game" (morphology condition) or a "matching game" (control condition). Participants were asked to respond as quickly and as accurately with a button press. Prior to testing, children completed a computer version of the task with a set of practice stimuli outside of the scanner.

Morphological awareness condition. In both English and Chinese, during each trial, participants heard two words consecutively. The first word was a child-friendly high-frequency real word while the second word was a morphologically derived new word, in which the new word either conformed to or violated morphological structures in the language of testing. Participants were asked to indicate with a button-press whether the new word was a good (acceptable) or bad (unacceptable) word.

The English condition was the same as in Arredondo et al. (2015) which was a derivational morphology task modeled after the Test of Morphological Structure task, which was previously shown to predict reading acquisition in English (Carlisle, 2000). During this condition, participants heard a real word (e.g., "jump" or "cow") and a new morphologically derived word that either conformed (e.g., "re-jump") or violated (e.g., "re-cow") the 
morphological structure in English. For instance, "re-jump" is acceptable because similar to re$d o$, the prefix $r e$-can be applied to verbs with the meaning that something was done again; conversely. Re-cow is unacceptable because prefix $r e$ - is affixed to verbs but not nouns. The English stimuli included morphemes typically tested during this age in combination with both verbs and nouns. The full list of experimental English stimuli is published in Arredondo et al. (2015).

The Chinese condition was a compound morphology task, modeled after the Chinese Morphological Construction task previously shown to predict reading acquisition in Chinese (McBride-Chang et al., 2003). During this condition participants heard a real word [e.g., “病人” (sick-man) or “雪人” (snow-man)] and a new word that resembled the first real word that either confirmed [e.g., “病花” (sick-flower)] or violated [e.g., “貓雪”, (cat-snow)] the structural constraints on morphological compounding in Mandarin Chinese. For instance, “病人” (sickman) - “病花” (sick-flower) is acceptable because in the order that the two morphemes are arranged, the morpheme “病” (sick) can modify the word “花” (flower); conversely for “雪人” (snow-man) - “貓雪” (cat-snow) word pair, “貓雪”, (cat-snow) is unacceptable because the ordering of the two morphemes is ungrammatical.

The study did not include compound morphology in English because unlike derivational morphology in English or compound morphology in Chinese, compounding in English is pragmatically rather than structurally-governed. In particular, in English, the second word in the compound is typically the "head" of the compound, as for instance a "snowman" is a type of man (Jackendoff, 2002, p. 249). Our piloting of the English task revealed that unlike Chinese speakers, English speakers were insensitive to prototypical versus unusual morpheme orderings within compound words (e.g., speakers judged both armball vs ballarm as equally acceptable options); therefore the English compound condition was omitted from the final experiment. For future studies, we recommend attempting sentential rather then single-word trials, so as to provide English speakers more contexts.

Control Word-Match condition. Participants completed a Word-Matching control condition in each language (within the same run). Similar to the experimental condition, participants heard two words, and then judged if the two words were the same or not (e.g. "table" - "table" = same; "muffin" - "sponge" = different). Within each language, the control stimuli 
were matched for sound and syllable length to the morphological awareness condition. We designed this control condition to best match the processes required for completing the experimental morphology condition, with the exception of the added effort for actively evaluating morphological structure.

Stimuli. For each language, words in the morphological awareness and word match control conditions were equated for number of syllables and phonemes. The English words were matched for American English frequency (http://subtlexus.lexique.org; Brysbaert \& New, 2009). In English, the words had an average of 4.5 phonemes, 1.5 syllables, and a verbal frequency of 66.5. In Chinese, the words were sampled from $1^{\text {st }}$ grade textbooks used in Chinese after-school programs in the area and had an average of 7.3 phonemes and 2.5 syllables. T-test comparisons between morphology and control condition within each language did not reveal statistical differences for any of these parameters $(p>.05)$.

English words were recorded by a female speaker who was a native to the Midwest region in the United States (same locale as the participants). Chinese words were recorded by a female native speaker of Mandarin Chinese, born and raised in People's Republic of China. All words were then filtered and normalized to 80-dB using Adobe Audition 1.5 software. The tasks were presented using Psychophysics Toolbox Version 3 in MATLAB (2010a, MathWorks). While in the fMRI, sounds were played using Pyle Home PCA1 30-Watt Stereo Mini Power amplifier to moderate the volume, and children wore Sensimetrics insert earphones model S14 and MRI non-magnetic earmuffs Ultra-33 to attenuate scanner noise and allow better quality of audio.

\section{Imaging Data Acquisition}

Image acquisition was collected using a 3-Tesla GE Signa scanner equipped with a quadrature head coil (General Electric, Milwaukee, WI). Participants used a button box to make responses. The tasks were projected onto a screen and participants wore goggles with built-in mirrors (VisuaStim XGA, Resonance Technologies) to view the display. Foam padding and a cloth forehead restraint were used to prevent head movement. A T1 overlay with Fast Gradient Echo Sequence 15 was conducted to obtain an anatomical image $(\mathrm{TR}=250 \mathrm{~ms}$, $\mathrm{TE}=5.7 \mathrm{~ms}$, flip angle $=90^{\circ}$, field of view $(\mathrm{FOV})=24 \mathrm{~cm}, 43$ slices $)$. Automatic slice prescription, based on alignment of localizer scans to a multi-subject atlas, was used to achieve a consistent head position across subjects. Functional T2* BOLD images were acquired with a spiral reverse only 
sequence. For each TR, $433 \mathrm{~mm}$ slices were captured $(\mathrm{TR}=2000 \mathrm{~ms}$, TE $=30 \mathrm{~ms}$, flip angle $=$ $90^{\circ}, \mathrm{FOV}=22 \mathrm{~cm}$, voxel size $\left.=3.44 \mathrm{~mm} \times 3.44 \mathrm{~mm} \times 3 \mathrm{~mm}\right)$.

\section{Imaging Data Pre-Processing}

Imaging data was processed and analyzed using SPM8 (Wellcome Department of Cognitive Neurology, London, UK) in MATLAB. We performed the following steps in the following order: slice timing, realignment, normalisation, and smoothing. There were a total of 218 TRs per language (excluding 4 dummy scans). After image reconstruction, each subject's data was realigned to the first functional volume using SPM8's spline interpolation. Movement parameters calculated by realignment were used to exclude volumes with potential artifacts. This procedure was implemented for each participant separately. Three of the 14 bilingual participants' data exceeded the criteria of having artifacts in more than $1 / 3$ of data volumes. The remaining bilinguals did not vary significantly in the number of artifactual volumes across English $($ mean $=29)$ and Chinese $($ mean $=45 ; t(9)=1.1, p=0.2)$. There were also no significant differences in the number of artifactual scans between monolinguals' (mean $=14)$ and bilinguals' English $(t(9)=3.4, p=0.08)$.

Sessions were then normalized using the mean functional volume into a standard EPI anatomical space; these were then resampled to fit Montreal Neurological Institute (MNI) stereotactic space. Spatial smoothing was done using a 6-mm full-width half-maximum Gaussian filter, which is a typical level for reducing noise that Hopfinger, Büchel, Holmes and Friston, (2000) have found to work best for examining data in the cortex. The data was then high-pass filtered with the standard $128 \mathrm{~s}$.

\section{Imaging Statistical Analyses}

Each subject's data was then analyzed using a fixed-effects model that included morphology and control conditions as the two factors. For each participant, BOLD response was then modeled using the dual-gamma canonical hemodynamic response function. Statistical images for the following contrasts were generated: control > rest, morphology > rest, control > morphology, and morphology > control. Second-level analyses were performed to obtain grouplevel contrast images, which were then examined using one-sample $t$-tests for whole-brain activations at an uncorrected threshold of $p<0.01$ and extent threshold (ET) of $>20$ voxels. To explore similarities in morphological processing across languages and groups, we used two conjunction analyses (morphology $>$ control contrasts, thresholded at $\mathrm{k}=20, p<0.05$, 
uncorrected): one for English in bilinguals and monolinguals and one for English and Chinese within bilinguals. The study uses a low statistical threshold to account for low bilingual participant numbers, which is unfortunate given that the study recruitment process took two years, resulting in an initial sample of 57 bilinguals who fit the strict criteria of dual language exposure and proficiency, of which only 14 families agreed to fMRI testing. In the end, we had to stop the laborious 2-year long recruitment and screening process when our imaging center switched to a new scanner. To the best of our knowledge, this is the first fMRI study of ChineseEnglish bilingual children, and one of a handful of fMRI studies of Chinese literacy with children (Brennan et al., 2012; Cao et al., 2010, 2011; Liu et al., 2013; Siok et al., 2008, 2004), and only one of two developmental Chinese studies to examine morphological awareness (Liu et al., 2013; Tong, Chung, \& McBride, 2014). Therefore, the evidence is likely to make a contribution to the field despite the relatively liberal threshold. Importantly, the results for the 11 English monolinguals that were drawn to match the bilinguals are consistent with the larger sample that was analyzed at a higher statistical threshold that was possible for a larger number of participants $(p<0.001, \mathrm{ET}=35$, corrected for multiple comparisons at $p<0.05$ (False Discovery Rate [FDR]) published in Arredondo et al. (2015).

ROI analyses. The few prior developmental fMRI studies of morphological processing suggest that left IFG, MFG and MTG regions might be key to children's morphological processing in English (Arredondo, Ip, Shih Ju Hsu, Tardif, \& Kovelman, 2015; Aylward et al., 2003) and in Chinese (Liu et al., 2013). Thus, the study includes a closer examination of children's brain activity in these regions by analyzing regions of interest (ROIs). The ROI coordinates were derived from the results of the conjunction analyses (morphology $>$ control contrasts; Figure 2/Table 5), yielding IFG BA $47(x=-36 y=18 z=-6), \operatorname{MFG}(x=-52 y=18 z$ $=34)$, and MTG $(x=-46 y=-44 z=6)$ regions. Conjunction analyses in English for bilinguals and monolinguals yielded the same regions, plus IFG BA45 ( $\mathrm{x}=-46 \mathrm{y}=22 \mathrm{z}=16)$ region. We used MarsBaR toolbox (Brett, Anton, Valabregue, \& Poline, 2002) in SPM8 to create 8-mm spheres and extract these regions' beta values from the morphology > rest and control > rest contrasts for each group and language task. During ROI extraction, the data was normalized using a hemodynamic response function and the temporal derivative to extract the percent signal change of contrast images (see http://marsbar.sourceforge.net/ for more details). The ROI analyses included ad-hoc between group/language t-test comparisons as well as Pearson 
correlations between participants' ROI activations and their performance on single word reading and behavioral morphological awareness tasks.

\section{Results}

\section{Behavioral Results}

Children's morphological awareness and reading competence. There were no significant differences between monolinguals and bilinguals on any behavioral measure or inscanner task performance in English $(p>0.05)$. In each language, children were significantly faster and more accurate during the control task (word matching) than the morphological awareness task (bilinguals in Chinese response time [RT]/accuracy: $t(9)=3.41 / 3.06, p=.01 / .01$, bilinguals in English RT/accuracy: $t(9)=3.02 / 5.28, p=.01 /<.001$; monolingual English RT/accuracy: $t(9)=3.28 / 8.09, p<.001$; table 1$)$.

The study's first behavioral prediction was that bilingual exposure to Chinese would strengthen children's associations between lexico-semantic (morphological awareness and vocabulary) and single-word reading abilities (bilingual transfer hypothesis). The study's second behavioral prediction was that early and systematic bilingual exposure should allow children to form language-specific representations of each of their languages (language-specific development hypothesis). These were tested with age-controlled partial correlations as well as multiple linear regressions using children's lexico-semantic (morphological awareness and vocabulary) and phonological (phonological awareness) abilities to predict singe-word reading in each of the children's languages. These analyses included 77 monolinguals and 57 bilinguals who successfully completed word reading, vocabulary as well as phonological and morphological awareness tasks in English. Of the full bilingual sample, only 51 bilinguals successfully completed the same four measures in Chinese.

As can be seen in Table 2, age-controlled correlations revealed that morphological awareness in all groups/languages was significantly associated with phonological awareness and vocabulary measures. There was also a significant relationship between children's single-word reading and morphological awareness in all groups/languages. Finally, only in bilinguals performing tasks in English was there a significant correlation between vocabulary and phonological awareness. There were also cross-linguistic correlations in bilinguals' measures of phonological and morphological awareness. Specifically, bilinguals' phonological awareness in English was associated with phonological awareness in Chinese, as was morphological 
awareness in English and Chinese. This is an important validation that measures of the same construct (morphology, phonology) correlate across bilinguals' two languages and offers additional evidence to support cross-linguistic transfer hypothesis.

As can be seen in Table 3, multiple linear regression models revealed that English literacy in English monolinguals was best predicted by children's vocabulary and phonological awareness. For bilinguals, English literacy was best predicted by vocabulary alone. For bilinguals performing tasks in Chinese, literacy was best predicted by phonological awareness. However, please note the near-ceiling performance for the Chinese morphology task (Table 1), which is likely the reason as to why morphology was not a significant predictor of Chinese literacy despite its significant correlation with literacy in Chinese.

\section{Brain Imaging Results}

\section{Children's brain bases of morphological awareness (Morphology > Control). In}

Chinese, bilinguals showed significant activation in left IFG (BA 47), MFG (BA 9), SFG (BA 6/8), as well as posterior STG and MTG (BA 21/22) regions. In English, bilinguals showed significant activation in left frontal IFG (BA 47/45), MFG (BA 9), SFG (BA 8) and posterior STG/MTG (BA 21/22) regions. English monolinguals showed significant activation in bilateral ventral IFG (BA 47/45), left MFG (BA 9), SFG (BA 6), left Inferior Parietal Lobe (IPL; BA 40), as well as bilateral posterior STG/MTG regions (Fig. 1, Tables 4a and 4b).

Similarities in brain bases for morphological awareness across English and Chinese were explored using conjunction analyses with morphology > match contrasts in bilinguals. These revealed significant similarities in left hemisphere regions including the ventral IFG, MFG, SFG and STG/MTG regions (Fig. 2, Table 5). Similarly, similarities in brain bases for morphological awareness across bilinguals and monolinguals were explored using conjunction analyses with morphology > match contrasts in English in bilinguals and monolinguals. These revealed significant similarities in left hemisphere regions including dorsal and ventral IFG, MFG, IPL and STG/MTG regions (Fig. 2, Table 5).

ROI analyses. Differences between Languages/Conditions. Pairwise $t$-test comparisons using morphology > rest contrasts for the bilingual group, revealed that bilinguals showed greater activation in IFG BA45 during the morphology condition in English, in comparison to Chinese $(t(9)=2.6, p=0.02)$. There were no other significant within-group differences $(p>$ 0.05). Independent sample $t$-test comparisons of English morphology > rest contrasts between 
bilinguals and monolinguals revealed that bilinguals had significantly more activation than monolinguals in the MTG region $(t(9)=-2.2, p<0.05)$; there were no other significant between group differences $(p>0.05)$. To limit the number of statistical comparisons and to avoid the ambiguity of double-subtractions, we did not analyze the word match control > rest or task > control values, nevertheless the control condition data plotted in Figure 3 suggests that the findings are consistent with the control condition as well.

Brain-Behavior Correlations. To examine the relationship between children's brain activation during the morphology awareness task and their literacy competence, we conducted Pearson correlations between the ROI beta-values (morphology > word match contrasts) and children's performance on word reading (word and character ID), and behavioral morphological and phonological awareness tasks. In English, bilinguals with better reading and morphological abilities had less activation in the left MTG region ( $\mathrm{r}=-.63$ and $\mathrm{r}=-.87, p<0.05$, respectively) and left IFG/BA 45 regions ( $\mathrm{r}=-.60$ and $\mathrm{r}=-.71, p<0.05$; respectively). Monolingual English speakers and bilinguals in Chinese also showed negative correlations between reading proficiency and left MTG activations (English in monolinguals $r=-.39$; Chinese in bilinguals $r=$ -.37), but these and other correlations did not reach statistical significance $(p>0.05)$.

\section{Discussion}

Bilingualism is a typical linguistic experience, yet relatively little is known about its impact on brain organization for learning to speak and to read. The aim of the present study was to examine the impact of bilingual exposure to Chinese on Chinese-English bilinguals' literacy and neural organization for morphological awareness, a critical literacy skill that is especially important for learning to read in Chinese. Our primary hypothesis was that bilingual exposure to Chinese would impact children's lexico-semantic abilities for learning to read in English.

Consistent with this hypothesis, as compared to English monolinguals, the bilinguals showed stronger associations between morphological and literacy competence, stronger activation in left MTG region typically associated with lexico-semantic processing as well as significant correlations between MTG activity and reading abilities in English. Our second hypothesis was that early and systematic bilingual exposure should allow bilinguals to develop language-specific cognitive bases for literacy and morphological competence in each of their languages. Consistent with this prediction, the bilinguals showed that literacy in each of their languages was best predicted by literacy skills in that language. Moreover, similar to English monolinguals, the 
bilinguals showed as well as greater activation in left dorsal IFG (BA 45/44) region in English than Chinese. Taken together the findings suggest that bilingual exposure to structurally distinct languages such as English and Chinese can both have a significant impact on children's literacy in English as well as allow young bilinguals to form language-specific representations.

In light of the bilingual transfer hypotheses (Cummins et al., 2011), our first prediction was that bilingual exposure to Chinese, a language that places great emphasis on lexical morphology to process words in speech and print (Perfetti et al., 2005), would strengthen children's associations between lexico-semantic and word reading skills. Indeed, ChineseEnglish bilinguals showed evidence of stronger meaning-to-print associations and weaker soundto-print associations in English as compared to English monolinguals. In particular, both bilinguals and monolinguals showed significant correlations between lexico-semantic abilities (vocabulary and morphological awareness) and literacy as well as between phonological abilities (phonological awareness) and literacy. Yet, multiple linear regression analyses revealed that vocabulary was a stronger predictor in bilinguals' English literacy than in monolinguals. Moreover, phonological awareness was a significant predictor of English literacy in monolinguals only. These findings were likely a result of the bilingual experiences with differing word structures of Chinese and English, differences that make lexico-semantic analyses an especially salient feature of lexical processing in Chinese (see introduction; Perfetti et al., 2005).

Our second prediction for the bilingual transfer hypothesis was that bilingual exposure to Chinese, a language that places great emphasis on lexical morphology to process words in speech and print (Perfetti et al., 2005), would impact the functionality of brain regions that process word meanings. Indeed, ROI analyses revealed that during the morphological awareness task in English the bilinguals had significantly stronger activations in left MTG region typically associated with sematic processing. The dysfunction of this region might relate to morphological awareness deficits in dyslexia in Chinese (Tong et al., 2014). In bilinguals, brain activation in left MTG and IFG (BA 45) were significantly related to bilinguals' English literacy. Bilinguals with better English literacy showed lower activation in these regions. The correlational trends were similar for Chinese in bilinguals and English in monolinguals (albeit not significant), and are commensurate with prior findings on monolinguals suggesting that reduced activation in these regions might be an index of increased automaticity in language and orthographic processing (Hoeft et al., 2007; Martin et al., 2015). Taken together, the combined behavioral and 
neuroimaging evidence suggests that the structural characteristics of bilinguals' heritage language (Chinese) can have a significant impact on children's literacy and neural architecture for learning to read in children's dominant language of reading instruction (English).

It is commonly assumed that children with early and systematic exposure to two languages form language-specific representations for each of their languages (De Houwer, 2005). Here we extended this hypothesis to test whether early-exposed bilinguals also form language-specific representations for learning to read. Consistent with our predictions, the behavioral evidence revealed that bilinguals' literacy in English was best predicted by English language abilities while bilinguals' literacy in Chinese was best predicted by Chinese language abilities. There were significant correlations between children's morphological and phonological abilities across the two languages, but no correlation between these abilities in one language and word reading abilities in the other language. One caveat was that phonological but not morphological awareness was a significant predictor of children's literacy in Chinese. We believe this was due to the near-ceiling effects for the Chinese morphological awareness task, an unfortunate limitation of the present study.

Can young bilinguals form language-specific patterns of brain activation for morphological awareness in each of their languages? Neuroimaging findings in the present study revealed that similar to English monolinguals, bilinguals showed stronger activation in left dorsal IFG (BA 45/44) in English than in Chinese. In English, syllables can be lexical morphemes (lexical: bak-er), syntactic morphemes (jump-ing), or meaningless phonological units (flow-er). Therefore, it is possible that greater activation in left dorsal IFG, a region considered key for phonological and syntactic analyses (Friederici \& Gierhan, 2013), reflects the characteristics of morpho-phonological analyses of words in English. The key finding here is that young bilinguals' brains are sensitive to the differential characteristics of lexical morphology in their two languages.

Cross-linguistic research comparing monolinguals' patterns of brain activity during word reading generally finds greater MFG (BA 9) and ventral IFG (BA 47/45) activation in Chinese relative to English readers, and greater activation in dorsal left IFG BA (45/44) in English (Tan et al., 2003; 2005). Here we do not find differences in activation in MFG and IFG (BA 47/45) regions between the two languages, possibly because these were auditory rather than visual tasks and the greater left MFG activation in Chinese is typically attributed to the verbal working 
memory load required for having to retrieve and map an entire morphemic unit onto a complex character representation. Another possible explanation is that we asked the participants to focus on the constituent morphemic structure of polymorphic words, which is a key feature of Chinese word processing in general (Perfetti et al., 2005), thereby equating the lexico-semantic and verbal working memory demands for left MFG and ventral IFG regions across the two languages. In sum, the cross-linguistic differences found in the field for word reading across languages could, at least in part, reflect language-specific characteristics of underlying word structure analyses (Seidenberg, 2011).

Psycholinguistic models of bilingual language processing often suggest that bilinguals form an integrated dual language lexicon (Kroll et al., 2015). The integrated conceptualization of the bilingual lexicon nevertheless leaves room for language-specific sublexical processes as well as language-specific factors of proficiency and the concomitant cognitive efforts for working with a low-proficiency language (van Heuven \& Dijkstra, 2010). Neuroimaging studies of bilingual language organization in adults often consider the differences in activation patterns between bilinguals' two languages as evidence of early language acquisition and/or high dual language proficiency (Consonni et al., 2013; Perani \& Abutalebi, 2005). In contrast to this line of reasoning about bilingual language organization, we have attributed the differences in left IFG (BA 45/44) brain activation between the bilinguals' two languages to the differences in derivational morphology demands in English and compound morphology demands in Chinese. Nevertheless, it remains possible that these differences were due to bilinguals' better English than Chinese language competence at the time of testing and therefore more efficient recruitment of computational resources of the left IFG regions in English. As the ultimate goal of neuroimaging work is to inform models of language organization, future research should include Chinese monolinguals as well as more balanced Chinese-English bilinguals. In combination with the present findings, these additional groups will help better adjudicate the neural mechanisms that represent the neural signature of language dominance and proficiency (Abutalebi et al., 2007) versus language-specific mechanisms typical of monolingual Chinese language processing.

On the one hand, our findings are consistent with our hypothesis that early bilingual exposure to Chinese, a language with salient lexico-semantic features in speech and in print, might change the functionality of bilinguals' brain regions for processing meaning. On the other 
hand, alternative explanations for bilinguals' greater left MTG activation than in monolinguals are also possible. One of the likeliest alternative explanations is bilinguals' greater lexicosemantic growth in English than in Chinese, and greater in bilinguals than in monolinguals. For instance, research finds that starting at around age 5, bilinguals' vocabulary growth in the language of schooling begins to outpace their vocabulary development in the heritage language (Sheng, 2014), possibly due to the increased social and academic pressure to catch-up to the monolingual speakers of their school language. Moreover, researchers studying single word reading in Spanish-English bilinguals have also found that in comparison to child bilinguals, adult bilinguals exhibited greater left MTG activation in English, the language in which bilingual adults had better reading competence than bilingual children (Hernandez, Woods \& Bradley, 2015). Yet, these adult bilinguals did not show greater left MTG activation relative to child bilinguals in Spanish, the language in which bilingual children and adults had similar reading competence. It is therefore possible that the bilinguals in our study also had greater rates of lexical growth in English than in Chinese and stronger in bilinguals than in monolinguals, which had resulted in bilinguals having significant correlations between left MTG activation and literacy in English, but not in Chinese and not in monolinguals. It is also possible that bilinguals' greater activation in left MTG region in English as compared to monolinguals was not due to the bilingual experiences with Chinese (as we had hypothesized), but rather due to bilingual childiren having to make rapid acquisition gains in English. To better adjudicate the languagespecific and language-general effects of bilingual exposure, future research should therefore consider inclusion of different bilingual language groups.

Importantly, the present study also has several significant caveats. First, the study's conclusions are limited by the small participant numbers. Second, the cross-linguistic comparisons are limited by the fact that we used derivational morphology tasks in English but compound morphology tasks in in Chinese. Third, we aimed to make inferences about the role of morphological awareness for learning to read but we only used auditory tasks of morphological awareness. Finally, across groups and languages, the children also showed significant activation in the left superior-frontal (pre-somatosensory cortex) region typically associated with response selection (e.g., Guo, Liu, Misra, \& Kroll, 2011). It is therefore important to note that the observed increases in activation during the morphological awareness condition relative to the 
control condition may have been due to the morphology tasks' greater lexico-semantic demands and/or the greater overall cognitive load for the harder task.

\section{Conclusions}

In support of the idea that young bilinguals can "transfer" language abilities for learning to read across their two languages, we present converging behavioral and neuroimaging evidence to suggest that even bilinguals learning such typologically different languages such as English and Chinese can form shared cognitive bases for morphological competence in two languages, especially in regions typically associated with lexicosemantic processing. Moreover, crosscultural theoretical perspectives on language and literacy suggest that children's neural networks accommodate the specific demands of their linguistic system, leading to differences in the brain networks for languages like English and Chinese (Perfetti, Cao, \& Booth, 2013). Our findings suggest that young bilingual children with early and systematic exposure can also form language-specific competence and patterns of brain activity for morphological awareness abilities that best characterize each of their languages. Importantly, the findings offer evidence to suggest that the bilinguals' two languages interact, with children's heritage language structure making a language-specific impact on children's emergent literacy skills and neural architecture for learning to read in their dominant language of reading instruction.

\section{References}

Abutalebi,J., Brambati, S. M., Annoni, J. M., Moro, A., Cappa, S. F., \& Perani, D. (2007). The neural cost of the auditory perception of language switches: An event-related functional magnetic resonance imaging study in bilinguals. The Journal of Neuroscience, 27(50), 13762-13769.

Apel, K., Diehm, E., \& Apel, L. (2013). Using multiple measures of morphological awareness to assess its relation to reading. Topics in Language Disorders, 33(1), 42-56.

Arredondo, M. M., Hu, X.-S., Satterfield, T. and Kovelman, I. (2016), Bilingualism alters children's frontal lobe functioning for attentional control. Developmental Science. doi: 10.1111/desc.12377

Arredondo, M. M., Ip, K. I., Shih Ju Hsu, L., Tardif, T., \& Kovelman, I. (2015). Brain bases of morphological processing in young children. Human Brain Mapping. http://doi.org/10.1002/hbm.22815/full 
Aylward, E. H., Richards, T. L., Berninger, V. W., Nagy, W. E., Field, K. M., Grimme, A. C., ... Cramer, S. C. (2003). Instructional treatment associated with changes in brain activation in children with dyslexia. Neurology, 61(2), 212-219.

Bialystok, E. (2013). 25 The Impact of Bilingualism on Language and Literacy Development. The Handbook of Bilingualism and Multilingualism, 624.

Bialystok, E., Luk, G., \& Kwan, E. (2005). Bilingualism, Biliteracy, and Learning to Read: Interactions Among Languages and Writing Systems. Scientific Studies of Reading, 9(1),43-61. http://doi.org/10.1207/s1532799xssr0901_4

Bozic, M., Tyler, L. K., Su, L., Wingfield, C., \& Marslen-Wilson, W. D. (2013). Neurobiological systems for lexical representation and analysis in English. Journal of Cognitive Neuroscience, 25(10), 1678-1691.

Brennan, C., Cao, F., Pedroarena-Leal, N., McNorgan, C., \& Booth, J. R. (2012). Reading acquisition reorganizes the phonological awareness network only in alphabetic writing systems. Human Brain Mapping, n/a-n/a. http://doi.org/10.1002/hbm.22147

Brett, M., Anton, J.-L., Valabregue, R., \& Poline, J.-B. (2002). Region of interest analysis using the MarsBar toolbox for SPM 99. Neuroimage, 16(2), S497.

Brysbaert, M., \& New, B. (2009). Moving beyond Kučera and Francis: A critical evaluation of current word frequency norms and the introduction of a new and improved word frequency measure for American English. Behavior Research Methods, 41(4), 977990.

Cao, F., Khaild, K., Lee, R., Brennan, C., Yang, Y., Li, K., ... Booth, J. R. (2011). Development of brain networks involved in spoken word processing of Mandarin Chinese. NeuroImage, 57(3), 750-759. http://doi.org/10.1016/j.neuroimage.2010.09.047

Cao, F., Lee, R., Shu, H., Yang, Y., Xu, G., Li, K., \& Booth, J. R. (2010). Cultural Constraints on Brain Development: Evidence from a Developmental Study of Visual Word Processing in Mandarin Chinese. Cerebral Cortex, 20(5), 1223-1233. http://doi.org/10.1093/cercor/bhp186 
Carlisle, J. F. (2000). Awareness of the structure and meaning of morphologically complex words: Impact on reading. Reading and Writing, 12(3), 169-190. http://doi.org/10.1023/A:1008131926604

Carlisle, J.F., \& Goodwin, A. P. (2013). Morphemes matter: How morphological knowledge contributes to reading and writing. Handbook of Language and Literacy: Development and Disorders, 265-282.

Cheung, P. S. P., Lee, K. Y. S., \& Lee, L. W. T. (1997). The development of the "Cantonese Receptive Vocabulary Test" for children aged 2-6 in Hong Kong. International Journal of Language \& Communication Disorders, 32(1), 127-138. http://doi.org/10.3109/13682829709021465

Consonni, M., Cafiero, R., Marin, D., Tettamanti, M., Iadanza, A., Fabbro, F., \& Perani, D. (2013). Neural convergence for language comprehension and grammatical class production in highly proficient bilinguals is independent of age of acquisition. Cortex, 49(5), 1252-1258.

Costa, A., \& Sebastián-Gallés, N. (2014). How does the bilingual experience sculpt the brain?. Nature Reviews Neuroscience, 15(5), 336-345.

Cummins, J. (2001). Bilingual children's mother tongue: Why is it important for education. Sprogforum, 19, 15-20.

Das, T., Padakannaya, P., Pugh, K. R., \& Singh, N. C. (2011). Neuroimaging reveals dual routes to reading in simultaneous proficient readers of two orthographies. NeuroImage, 54(2), 1476-1487. http://doi.org/10.1016/j.neuroimage.2010.09.022 Deacon, S. H. (2012). Bringing development into a universal model of reading. Behavioral and Brain Sciences, 35(05), 284-284. http://doi.org/10.1017/S0140525X12000040

De Houwer, A. (2005). Early bilingual acquisition separate development hypothesis. In J. F. Kroll \& A. d. Groot (Eds.), Handbook of bilingualsim (pp. 30-48). New York: Oxford.

Ehri, L. C. (2014). Orthographic mapping in the acquisition of sight word reading, spelling memory, and vocabulary learning. Scientific Studies of Reading, 18(1), 5-21. 
Friederici, A. D. (2012). The cortical language circuit: from auditory perception to sentence comprehension. Trends in Cognitive Sciences, 16(5), 262-268.

Friederici, A. D., \& Gierhan, S. M. (2013). The language network. Current Opinion in Neürobiology, 23(2), 250-254.

Grosjean, F. (1989). Neurolinguists, beware! The bilingual is not two monolinguals in one person. Brain and Language, 36(1), 3-15. http://doi.org/10.1016/0093934X(89)90048-5

Guo, T., Liu, H., Misra, M., \& Kroll, J. F. (2011). Local and global inhibition in bilingual word production: fMRI evidence from Chinese-English bilinguals. NeuroImage, 56(4), $2300-2309$.

Hammer, C. S., Hoff, E., Uchikoshi, Y., Gillanders, C., Castro, D. C., \& Sandilos, L. E. (2014). The language and literacy development of young dual language learners: A critical review. Early Childhood Research Quarterly, 29(4), 715-733.

Hernandez, A. E., \& Li, P. (2007). Age of acquisition: its neural and computational mechanisms. Psychological Bulletin, 133(4), 638.

Hernandez, A. E., Woods, E. A., \& Bradley, K. A. (2015). Neural correlates of single word reading in bilingual children and adults. Brain and Language, 143, 11-19.

Hickok, G., \& Poeppel, D. (2007). The cortical organization of speech processing. Nature Reviews Neuroscience, 8(5), 393-402.

Hoeft, F., Meyler, A., Hernandez, A., Juel, C., Taylor-Hill, H., Martindale, J. L., ... Gabrieli, J. D. E. (2007). Functional and morphometric brain dissociation between dyslexia and reading ability. Proceedings of the National Academy of Sciences, 104(10), 42344239. http://doi.org/10.1073/pnas.0609399104

Hopfinger, J. B., Büchel, C., Holmes, A. P., \& Friston, K. J. (2000). A study of analysis parameters that influence the sensitivity of event-related fMRI analyses. Neuroimage, 11(4), 326-333.

Jackendoff, R. (2002). Foundations of language: Brain. Meaning, Grammar, Evolution. Oxford University Press. 
Jamal, N. I., Piche, A. W., Napoliello, E. M., Perfetti, C. A., \& Eden, G. F. (2012). Neural basis of single-word reading in Spanish-English bilinguals. Human Brain Mapping, 33(1), 235-245. http://doi.org/10.1002/hbm.21208

Kaufman, A., \& Kaufman, N. (2004). Kaufman Brief Intelligence Test, Second Edition (KBIT2) (2nd ed.).

Kovelman, I., Baker, S. A., \& Petitto, L.-A. (2008). Bilingual and monolingual brains compared: a functional magnetic resonance imaging investigation of syntactic processing and a possible "neural signature" of bilingualism. Journal of Cognitive Neuroscience, 20(1), 153-169.

Kovelman, I., Shalinsky, M. H., Berens, M. S., \& Petitto, L. A. (2014). Words in the bilingual brain: an fNIRS brain imaging investigation of lexical processing in sign-speech bimodal bilinguals. Frontiers in human neuroscience, 8, 606.

Kroll, J. F. (2015). On the consequences of bilingualism: We need language and the brain to understand cognition. Bilingualism: Language and Cognition, 18(01), 32-34.

Liu, L., Tao, R., Wang, W., You, W., Peng, D., \& Booth, J. R. (2013). Chinese dyslexics show neural differences in morphological processing. Developmental Cognitive Neuroscience, 6, 40-50.

Liu, L., Vira, A., Friedman, E., Minas, J., Bolger, D., Bitan, T., \& Booth, J. (2010). Children with reading disability show brain differences in effective connectivity for visual, but not auditory word comprehension. PloS One, 5(10), e13492. http://doi.org/10.1371/journal.pone.0013492

Luk, G., \& Bialystok, E. (2008). Common and distinct cognitive bases for reading in EnglishCantonese bilinguals. Applied Psycholinguistics, 29(02), 269-289.

Martin, A., Schurz, M., Kronbichler, M., \& Richlan, F. (2015). Reading in the brain of children and adults: A meta-analysis of 40 functional magnetic resonance imaging studies. Human Brain Mapping, 36(5), 1963-1981.

McBride, C. A. (2015). Is Chinese special? Four aspects of Chinese literacy acquisition that might distinguish learning Chinese from learning alphabetic orthographies. Educational Psychology Review, 1-27. 
McBride-Chang, C., Cho, J.-R., Liu, H., Wagner, R. K., Shu, H., Zhou, A., ... Muse, A. (2005).

Changing models across cultures: Associations of phonological awareness and morphological structure awareness with vocabulary and word recognition in second graders from Beijing, Hong Kong, Korea, and the United States. Journal of Experimental Child Psychology, 92(2), 140-160. http://doi.org/10.1016/j.jecp.2005.03.009

McBride-Chang, C., Lam, F., Lam, C., Chan, B., Fong, C. Y.-C., Wong, T. T.-Y., \& Wong, S. W.-L. (2011). Early predictors of dyslexia in Chinese children: Familial history of dyslexia, language delay, and cognitive profiles. Journal of Child Psychology and Psychiatry, 52(2), 204-211.

McBride-Chang, C., Shu, H., Chan, W., Wong, T., Wong, A. M.-Y., Zhang, Y., ... Chan, P. (2013). Poor Readers of Chinese and English: Overlap, Stability, and Longitudinal Correlates. Scientific Studies of Reading, 17(1), 57-70. http://doi.org/10.1080/10888438.2012.689787

McBride-Chang, C., Shu, H., Zhou, A., Wat, C. P., \& Wagner, R. K. (2003). Morphological Awareness Uniquely Predicts Young Children's Chinese Character Recognition. Journal of Educational Psychology, 95(4), 743-51.

Mechelli, A., Crinion, J. T., Noppeney, U., O'Doherty, J., Ashburner, J., Frackowiak, R. S., \& Price, C. J. (2004). Neurolinguistics: structural plasticity in the bilingual brain. Nature, 431(7010), 757-757.

Meschyan, G., \& Hernandez, A. E. (2006). Impact of language proficiency and orthographic transparency on bilingual word reading: An fMRI investigation. NeuroImage, 29(4), 1135-1140.

Newman, E. H., Tardif, T., Huang, J., \& Shu, H. (2011). Phonemes matter: the role of phoneme-level awareness in emergent Chinese readers. Journal of Experimental Child Psychology, 108(2), 242-259. http://doi.org/10.1016/j.jecp.2010.09.001

Nakamura, K., Kuo, W. J., Pegado, F., Cohen, L., Tzeng, O. J., \& Dehaene, S. (2012). Universal brain systems for recognizing word shapes and handwriting gestures during reading. Proceedings of the National Academy of Sciences, 109(50), 20762-20767. 
Ofen, N., Chai, X. J., Schuil, K. D., Whitfield-Gabrieli, S., \& Gabrieli, J. D. (2012). The development of brain systems associated with successful memory retrieval of scenes. The Journal of Neuroscience, 32(29), 10012-10020.

Perani, D., \& Abutalebi, J. (2005). The neural basis of first and second language processing. Current Opinion in Neurobiology, 15(2), 202-206. http://doi.org/10.1016/j.conb.2005.03.007

Perfetti, C. A., Liu, Y., \& Tan, L. H. (2005). The lexical constituency model: some implications of research on Chinese for general theories of reading. Psychological Review, $112(1), 43$.

Perfetti, C., Cao, F., \& Booth, J. (2013). Specialization and universals in the development of reading skill: How Chinese research informs a universal science of reading. Scientific Studies of Reading, 17(1), 5-21.

Ramirez, G., Chen, X., Geva, E., \& Luo, Y. (2011). Morphological awareness and word reading in English language learners: Evidence from Spanish-and Chinese-speaking children. Applied Psycholinguistics, 32(03), 601-618.

Seidenberg, M. S. (2011). Reading in different writing systems: One architecture, multiple solutions. Dyslexia across Languages. Baltimore: Brookes.

Sheng, L. (2014). Lexical-semantic skills in bilingual children who are becoming Englishdominant: A longitudinal study. Bilingualism, 17(3), 556-571.

Shu, H., Peng, H., \& McBride-Chang, C. (2008). Phonological awareness in young Chinese children. Developmental Science, 11(1), 171-181.

Siok, W. T., \& Fletcher, P. (2001). The role of phonological awareness and visualorthographic skills in Chinese reading acquisition. Developmental Psychology, $37(6), 886$.

Siok, W. T., Niu, Z., Jin, Z., Perfetti, C. A., \& Tan, L. H. (2008). A structural-functional basis for dyslexia in the cortex of Chinese readers. Proceedings of the National Academy of Sciences, 105(14), 5561-5566. http://doi.org/10.1073/pnas.0801750105

Siok, W. T., Perfetti, C. A., Jin, Z., \& Tan, L. H. (2004). Biological abnormality of impaired reading is constrained by culture. Nature, 431(7004), 71-76. http://doi.org/10.1038/nature02865 
Tan, L. H., Laird, A. R., Li, K., \& Fox, P. T. (2005). Neuroanatomical correlates of phonological processing of Chinese characters and alphabetic words: A meta-analysis. Human Brain Mapping, 25(1), 83-91. http://doi.org/10.1002/hbm.20134

Tan, L. H., Spinks, J. A., Feng, C.-M., Siok, W. T., Perfetti, C. A., Xiong, J., ... Gao, J.-H. (2003). Neural systems of second language reading are shaped by native language. Human Brain Mapping, 18(3), 158-166. http://doi.org/10.1002/hbm.10089

Tong, X., Chung, K. K. H., \& McBride, C. (2014). Two-character Chinese compound word processing in Chinese children with and without dyslexia: ERP evidence. Developmental Neuropsychology, 39(4), 285-301.

van Heuven, W. J., \& Dijkstra, T. (2010). Language comprehension in the bilingual brain: fMRI and ERP support for psycholinguistic models. Brain research reviews, 64(1), 104-122.

Wagner, R. K., Torgesen, J. K., \& Rashotte, C. A. (1999). Wagner, Richard K., Joseph K. Torgesen, and Carol Alexander Rashotte. Comprehensive test of phonological processing: CTOPP(Pro-Ed).

Wang, M., Lin, C. Y., \& Yang, C. (2014). Contributions of Phonology, Orthography, and Morphology in Chinese-English Biliteracy Acquisition: A One-Year Longitudinal Study. In Reading Development and Difficulties in Monolingual and Bilingual Chinese Children (pp. 191-211). Springer Netherlands.

Woodcock, R. W. (1998). Woodcock Reading Mastery Tests - Revised/Normative Update. Circle Pines, MN: American Guidance Service.

Zhang, J., McBride-Chang, C., Wagner, R. K., \& Chan, S. (2014). Uniqueness and overlap: Characteristics and longitudinal correlates of native Chinese children's writing in English as a foreign language. Bilingualism: Language and Cognition, 17(02), 347363.

Ziegler, J. C., \& Goswami, U. (2005). Reading Acquisition, Developmental Dyslexia, and Skilled Reading Across Languages: A Psycholinguistic Grain Size Theory. Psychological Bulletin, 131(1), 3-29. http://doi.org/10.1037/0033-2909.131.1.3 
Table 1.

\begin{tabular}{|c|c|c|c|c|c|}
\hline \multirow[b]{3}{*}{ English Measures } & \multirow{3}{*}{$\begin{array}{l}\text { Total } \\
\text { items }\end{array}$} & \multicolumn{2}{|c|}{ Bilingual } & \multicolumn{2}{|c|}{ Monolingual } \\
\hline & & Imaging Sample & Full Sample & Imaging Sample & Full Sample \\
\hline & & Mean Raw Score (SD) & Mean Raw Score (SD) & Mean Raw Score (SD) & Mean Raw Score (SD) \\
\hline & - & $9.58 \pm 1.39$ & $8.71 \pm 1.75$ & $9.67 \pm 1.51$ & $9.24 \pm 1.82$ \\
\hline Vocabulary & 60 & $31.36 \pm 7.90$ & $30.16 \pm 8.73$ & $34.36 \pm 8.20$ & $33.12 \pm 7.99$ \\
\hline Single Word Reading & 106 & $72.36 \pm 13.54$ & $70.21 \pm 13.54$ & $79.09 \pm 10.97$ & $70.34 \pm 18.59$ \\
\hline Phonological awareness & 20 & $16.18 \pm 3.12$ & $14.96 \pm 4.27$ & $16.46 \pm 2.94$ & $15.60 \pm 9.92$ \\
\hline Morphological awareness & 12 & $9.73 \pm 2.37$ & $9.07 \pm 2.15$ & $10.46 \pm .93$ & $9.57 \pm 1.97$ \\
\hline $\begin{array}{c}\text { In-Scanner Task } \\
\text { Accuracy (\% correct) }\end{array}$ & & & & & \\
\hline Morphological awareness & 24 & $77.65 \pm 16.17$ & $\mathrm{n} / \mathrm{a}$ & $73.11 \pm 13.09$ & $\mathrm{n} / \mathrm{a}$ \\
\hline Word-Match/Control & 24 & $95.45 \pm 6.30$ & $\mathrm{n} / \mathrm{a}$ & $92.05 \pm 14.00$ & $\mathrm{n} / \mathrm{a}$ \\
\hline
\end{tabular}




\begin{tabular}{|c|c|c|c|c|c|}
\hline \multicolumn{6}{|l|}{ Reaction Time (msec) } \\
\hline Morphological awareness & 24 & $2534.31 \pm 244.87$ & $\mathrm{n} / \mathrm{a}$ & $2543.43 \pm 175.58$ & $\mathrm{n} / \mathrm{a}$ \\
\hline Word-Match/Control & 24 & $2097.69 \pm 435.44$ & $\mathrm{n} / \mathrm{a}$ & $2326.10 \pm 266.19$ & $\mathrm{n} / \mathrm{a}$ \\
\hline \multirow[b]{3}{*}{ Chinese Measures } & \multirow[b]{3}{*}{$\begin{array}{l}\text { Total } \\
\text { items }\end{array}$} & \multicolumn{2}{|c|}{ Bilingual } & & \\
\hline & & \multicolumn{2}{|l|}{ Imaging Sample } & & \\
\hline & & Mean Raw Score (SD) & Mean Raw Score (SD) & & \\
\hline Vocabulary & 64 & $60.36 \pm 2.50$ & $56.23 \pm 5.18$ & & \\
\hline Single Word Reading & 120 & $24.90 \pm 11.29$ & $22.93 \pm 11.78$ & & \\
\hline Phonological awareness & 54 & $37.50 \pm 4.97$ & $34.86 \pm 9.54$ & & \\
\hline Morphological awareness & 30 & $25.27 \pm 3.85$ & $24.51 \pm 4.70$ & & \\
\hline In-Scanner Task & & & & & \\
\hline Accuracy (\% correct) & & & & & \\
\hline Morphological awareness & 24 & $85.58 \pm 14.17$ & $\mathrm{n} / \mathrm{a}$ & & \\
\hline Word-Match/Control & 24 & $96.67 \pm 4.30$ & $\mathrm{n} / \mathrm{a}$ & & \\
\hline In-Scanner RT (msec) & & & & & \\
\hline Morphological awareness & 24 & $2422.48 \pm 263.86$ & $\mathrm{n} / \mathrm{a}$ & & \\
\hline Word-Match/Control & 24 & $2198.58 \pm 330.84$ & $\mathrm{n} / \mathrm{a}$ & & \\
\hline
\end{tabular}


Table 2a. Partial Correlation controlling for Age between English Measures for English Monolinguals

\begin{tabular}{lllll}
\hline \hline Variables & 1 & 2 & 3 & 4 \\
\hline 1 Reading (Woodcock) & - & & & \\
2 Phonological Awareness (CTOPP-Elision) & $.62^{* * *}$ & - & & \\
3 Morphological Awareness & $.35^{* *}$ & $.25^{*}$ & - & \\
4 Vocabulary (KBIT) & $.37^{* * *}$ & .12 & $.45^{* * *}$ & - \\
\hline \hline
\end{tabular}

Note. ${ }^{*} p \leq .05 . * * p \leq .01 . * * * p \leq .001$.

Table 2b. Partial Correlation controlling for Age between Chinese and English Measures for Chinese-English Bilinguals

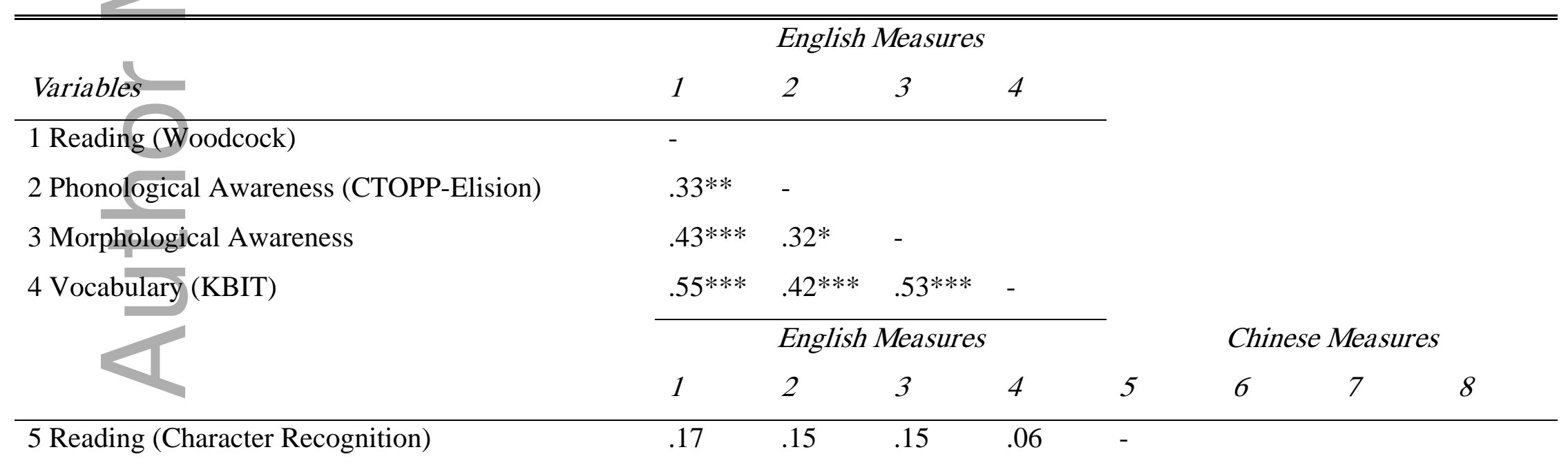

This article is protected by copyright. All rights reserved 


\begin{tabular}{llllllll}
6 Phonological Awareness & .18 & $.45^{* * *}$ & .15 & .14 & $.39 * *$ & - \\
7 Morphological Awareness & .21 & .14 & $.42^{* *}$ & .14 & $.35^{*}$ & $.35^{*}$ & - \\
8 Vocabulary (Picture Identification) & .06 & .12 & .20 & -.11 & $.37^{* *}$ & .20 & $.61^{* * *}-$ \\
\hline \hline
\end{tabular}

Note. ${ }^{*} p \leq .05 . * * p \leq .01 . * * * p \leq .001$.

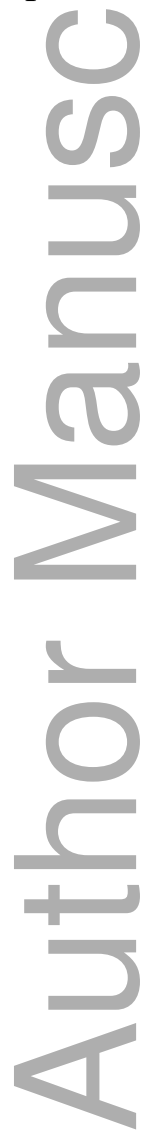

This article is protected by copyright. All rights reserved 
Table 3. Multiple Linear Regression Analyses Predicting Reading Performance

\begin{tabular}{|c|c|c|c|}
\hline ك- & $\begin{array}{l}\text { Monolingual English } \\
\qquad(n=75)\end{array}$ & $\begin{array}{l}\text { Bilingual English } \\
\qquad(n=57)\end{array}$ & $\begin{array}{c}\text { Bilingual Chinese } \\
(n=51)\end{array}$ \\
\hline Predictors & Standardized Beta & Standardized Beta & Standardized Beta \\
\hline Age & $.28 * *$ & .20 & $.26^{*}$ \\
\hline Vocabulary & $.34 * *$ & $.46^{* *}$ & .24 \\
\hline $\mathrm{PA}$ & $.42 * * *$ & .09 & $.30 *$ \\
\hline MA & .04 & .17 & $.07^{\wedge}$ \\
\hline Total $R^{2}$ & $.77 * * *$ & $.63 * * *$ & $.41 * * *$ \\
\hline
\end{tabular}

Note. $* p \leq .05 . * * p \leq .01 . * * * p \leq .001$; PA $=$ Phonological Awareness; MA = Morphological Awareness; ^likely due to ceiling performance on MA task

Table 4a.

Brain activations in bilinguals during Chinese and English Morphology Awareness tasks, relative to Match task (control) in Chinese and in English

\begin{tabular}{|c|c|c|c|c|c|c|}
\hline Regions & $\mathrm{H} \quad \mathrm{BA}$ & Voxels & $\mathrm{T}$ & $\mathrm{x}$ & $\mathrm{y}$ & $\mathrm{Z}$ \\
\hline \multicolumn{7}{|l|}{ Frontal Lobe } \\
\hline Inferior frontal gyrus & L 47 & 111 & 4.94 & -32 & 16 & -4 \\
\hline Middle frontal gyrus & L 9 & 20 & 3.31 & -52 & 16 & 30 \\
\hline & L 6 & 28 & 4.09 & 0 & 38 & 38 \\
\hline Superior medial frontal gyrus & L 8 & 47 & 3.92 & -8 & 38 & 52 \\
\hline \multicolumn{7}{|l|}{ Temporal lobe } \\
\hline Superior/middle temporal gyrus & $\mathrm{L}$ & 34 & 3.83 & -40 & -38 & 8 \\
\hline
\end{tabular}

This article is protected by copyright. All rights reserved 


\section{Frontal lobe}

\begin{tabular}{|c|c|c|c|c|c|c|c|}
\hline & & $45 /$ & & & & & \\
\hline Inferior frontal gyrus & $\mathrm{L}$ & 7 & 528 & 5.5 & -36 & 10 & 20 \\
\hline Middle frontal gyrus & $\mathrm{L}$ & 9 & 29 & 4.22 & -50 & 12 & 40 \\
\hline Medial frontal gyrus & $\mathrm{L}$ & 8 & 28 & 5.44 & -12 & 30 & 44 \\
\hline Temporal lobe & & & & & & & \\
\hline $\begin{array}{l}\text { Superior/middle temporal gyrus } \\
\text { Subcortical Area }\end{array}$ & $\mathrm{L}$ & 22 & 367 & 5.36 & -54 & -44 & -8 \\
\hline Cingulate gyrus & $\mathrm{L}$ & & 31 & 8.03 & -12 & -8 & 32 \\
\hline
\end{tabular}

Note. Abbreviations: H Hemisphere; BA Brodmann area. MNI coordinates are reported. $p<.01$ uncorrected, $\mathrm{ET}=20$.

Table 4b.

Brain activations in monolinguals during English Morphological Awareness relative to Control task

\begin{tabular}{llllllll}
\hline Regions & $\mathrm{H}$ & $\mathrm{BA}$ & Voxels & $\mathrm{T}$ & $\mathrm{x}$ & $\mathrm{y}$ & $\mathrm{z}$ \\
\hline Frontal lobe & & & & & & & \\
Inferior frontal gyrus & $\mathrm{L}$ & $47 / 38$ & 1311 & 7.11 & -42 & 30 & 30 \\
& $\mathrm{R}$ & 47 & 296 & 3.88 & 54 & 18 & -6 \\
Middle frontal gyrus & $\mathrm{L}$ & 9 & 190 & 4.16 & -44 & 12 & 40 \\
& $\mathrm{~L}$ & 9 & 47 & 3.33 & -54 & 26 & 24 \\
& $\mathrm{R}$ & 6 & 41 & 4.04 & 38 & -4 & 66 \\
Superior frontal gyrus & $\mathrm{L}$ & 6 & 2023 & 7.99 & -4 & 2 & 68 \\
Postcentral gyrus & $\mathrm{L}$ & 40 & 70 & 4.02 & -52 & -28 & 52 \\
Precentral gyrus & $\mathrm{R}$ & 6 & 44 & 3.65 & 36 & -18 & 70 \\
Temporal lobe & & & & & & & \\
Middle temporal gyrus & $\mathrm{L}$ & 20 & 42 & 4.41 & -54 & -40 & -14
\end{tabular}




\section{Parietal lobe}

$\begin{array}{llllllll}\text { Inferior parietal lobe } & \text { L } & 40 & 86 & 3.8 & -50 & -36 & 32\end{array}$

Occipital lobe

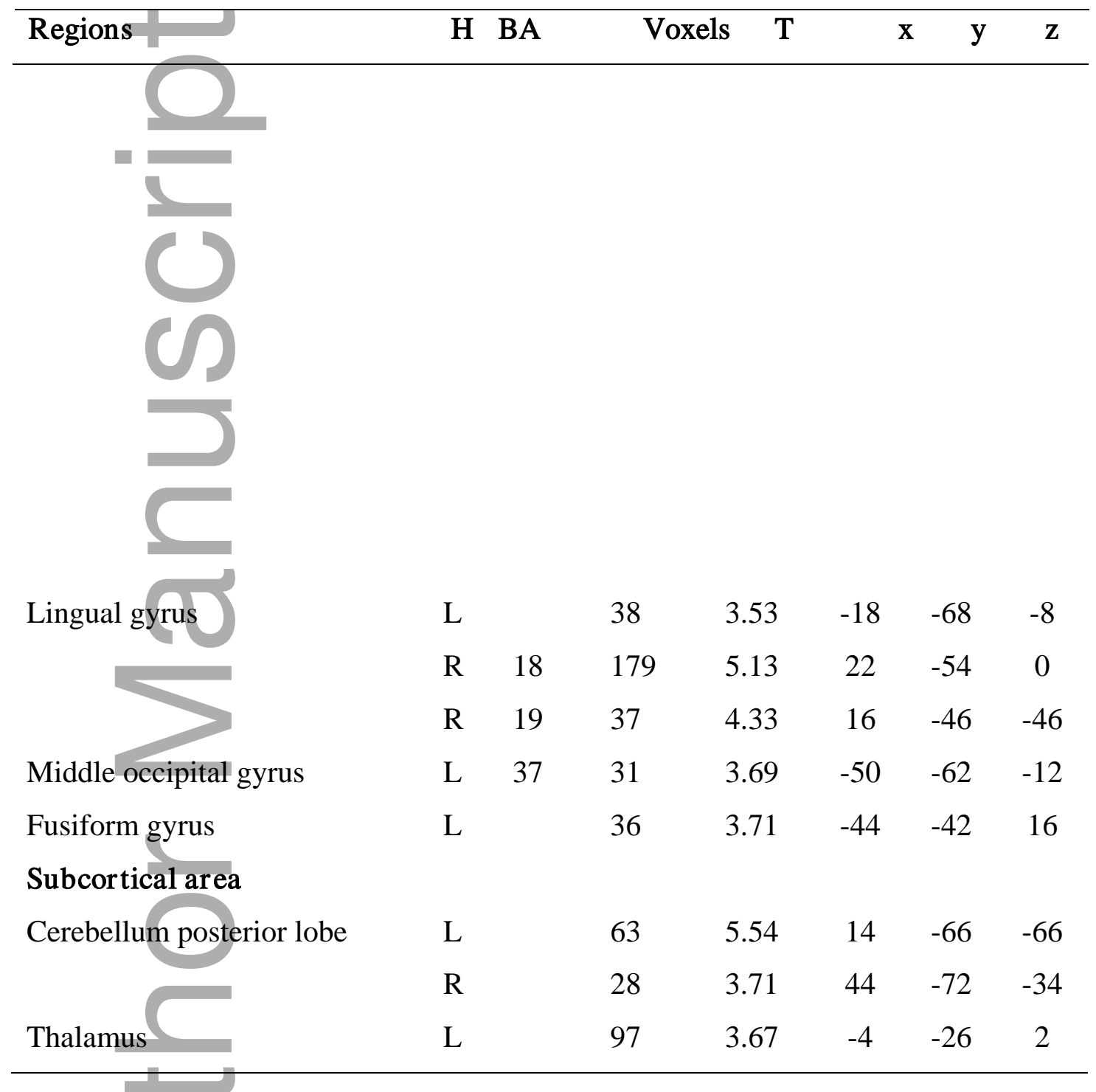

Note. Abbreviations: H Hemisphere; BA Brodmann area. MNI coordinates are reported. $p<.01$ uncorrected, $\mathrm{ET}=20$.

Table 5. Conjunction analysis the two languages of the bilinguals and English in bilinguals and monolinguals (morphology > control contrasts). 


\section{Bilingual Chinese and English morphological awareness}

\section{Frontal lobe}

Inferior frontal gyrus

L 47

341

$\begin{array}{llll}11.55 & -36 & 18 & -6\end{array}$

Superior medial frontal gyrus

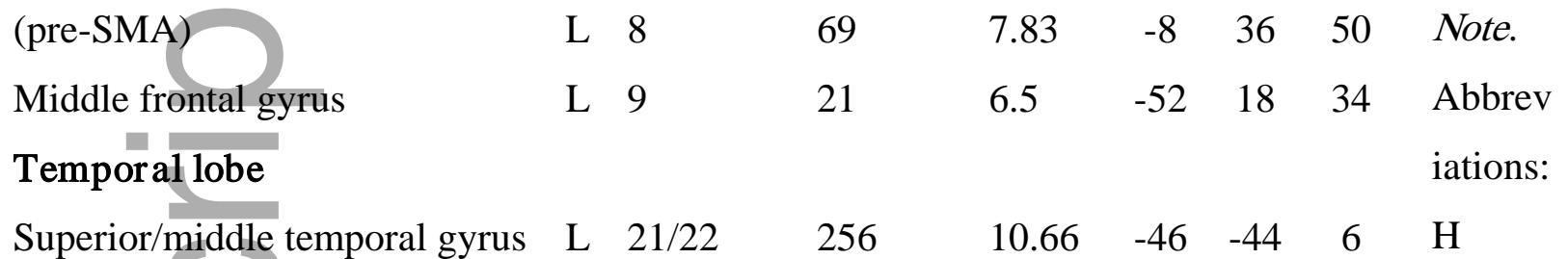

Bilingual and monolingual English morphological awareness

Hemisp

Frontal lobe here;

Inferior frontal gyrus

L 44/45/47 1084

$\begin{array}{llll}19.14 & -44 & 24 & 0\end{array}$

BA

Middle frontal gyrus

L 9

67

$\begin{array}{llll}12.12 & -48 & 14 & 38\end{array}$

Brodma

Medial frontal gyrus

L 6

27

6.7

Medial frontal gyrus

L 8

55

L 6

30

11.76

$-8 \quad 24$

Precentral gyrus

R 6

46

10.77

$-4 \quad 16$

40 nn area.

Precentral gyrus

Superior medial frontal gyrus

(pre-SMA)

L 6

58

$\begin{array}{llll}5.21 & 34 & -12 & 52\end{array}$

50

MNI

Temporal lobe

Superior temporal gyrus

L - 25

25

L 37

69

$\begin{array}{lllll}4.76 & -42 & -40 & 12 & \text { uncorre }\end{array}$

Middle temporal gyrus

37

$\begin{array}{lllll}9.59 & -54 & -40 & -14 & \text { cted. }\end{array}$

Parietal lobe

\begin{tabular}{lllllllll} 
Inferior parietal lobe & $\mathrm{L}$ & 40 & 22 & 5.39 & -38 & -40 & 52 & $\begin{array}{l}\text { threshol } \\
\mathrm{d}(\mathrm{ET})\end{array}$ \\
\cline { 1 - 1 } & & & & &
\end{tabular}




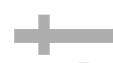

Figure 1. Bra

Figure Legends

contrasts; $p<0.01$ uncorrected).

Figure 2. Conjunction analyses for bilinguals' activations during morphological awareness in Chinese and English revealed common activations in left ventral IFG, MFG, SFG and STG/MTG regions. Conjunction analyses for English in bilinguals and monolinguals during morphological awareness revealed common activations in left dorsal and ventral IFG, MFG, SFG, IPL and STG/MTG (morphology $>$ control contrasts; $p<05$, uncorrected).

Figure 3. Brain activations in bilingual and monolingual participants during word match (control) condition relative to rest and morphological awareness condition relative to rest, as reflected in percent signal change (in beta values) for common regions of activation in English and Chinese, including IFG BA 47, MFG, MTG, in bilingual participants and the additional IFG BA 45 region that was common to English across bilingual and monolingual participants.

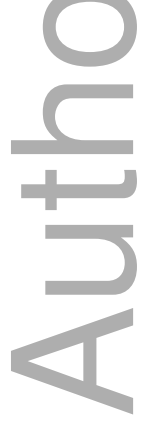

This article is protected by copyright. All rights reserved 

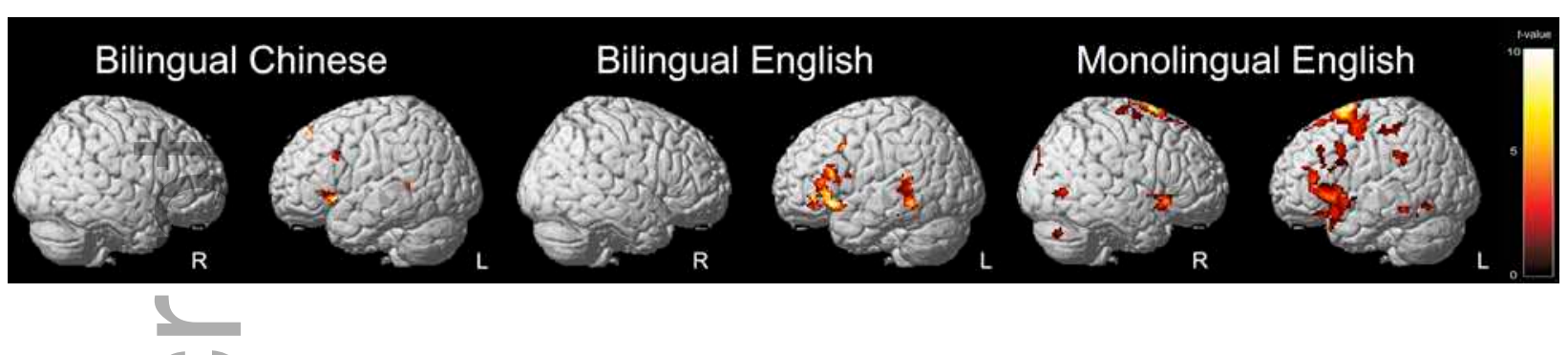

Figure 1. Brain activations in bilingual and monolingual participants during morphological awareness condition relative to match conditions $(p<0.01$ uncorrected).

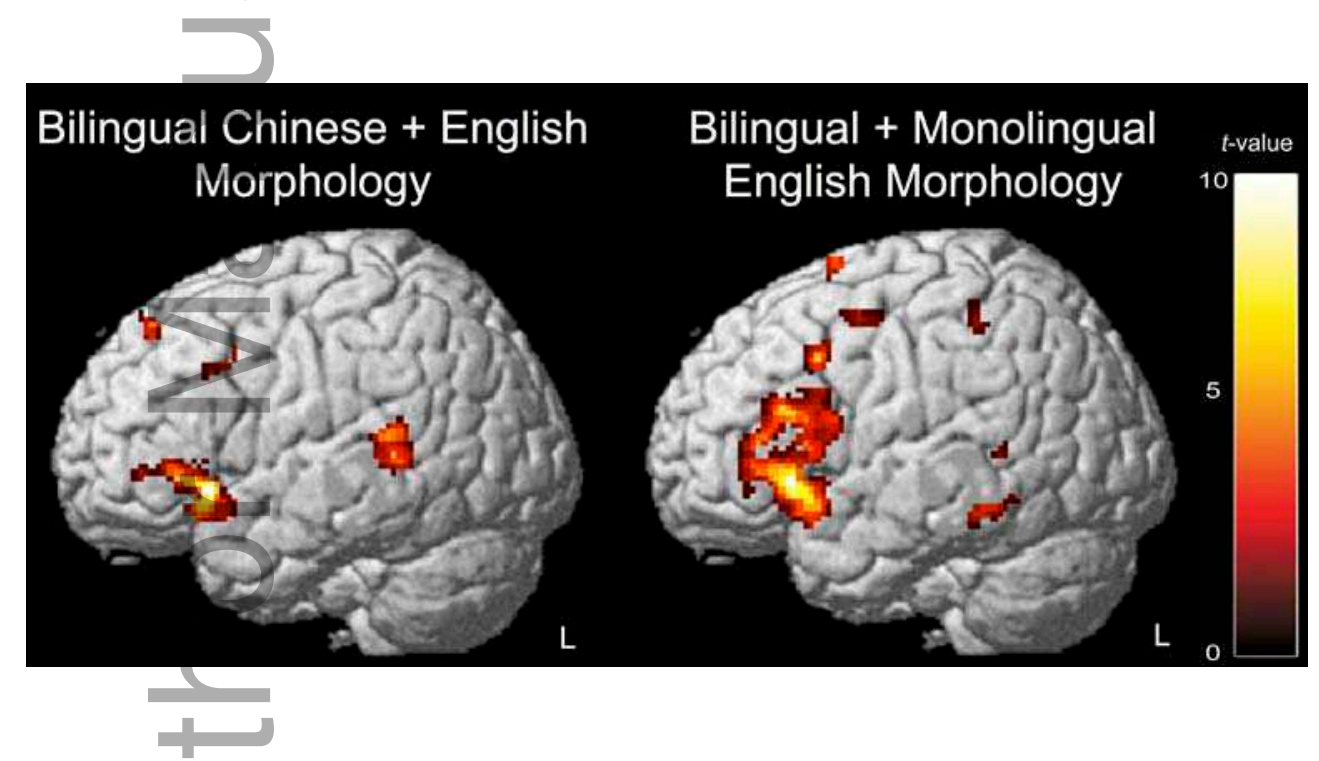

Figure 2. Conjunction analyses for bilinguals' activations during morphological awareness in Chinese and English revealed common activations in left ventral IFG, MFG, SFG and STG/MTG regions. Conjunction analyses for English in bilinguals and monolinguals during morphological awareness revealed common activations in left dorsal and ventral IFG, MFG, SFG, IPL and STG/MTG (morphology $>$ control contrasts; $p<05$, uncorrected). 


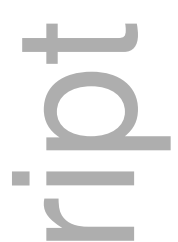

Figure 3. Brain activations in bilingual and monolingual participants during word match (control) condition relative to rest and morphological awareness condition relative to rest, as reflected in percent signal change (in beta values) for common regions of activation in English and Chinese, including IFG BA 47, MFG, MTG, in bilingual participants and the additional IFG BA 45 region that was common to English across bilingual and monolingual participants.

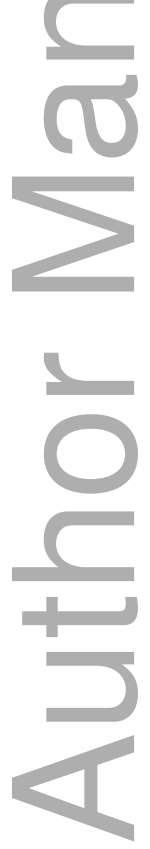

This article is protected by copyright. All rights reserved 

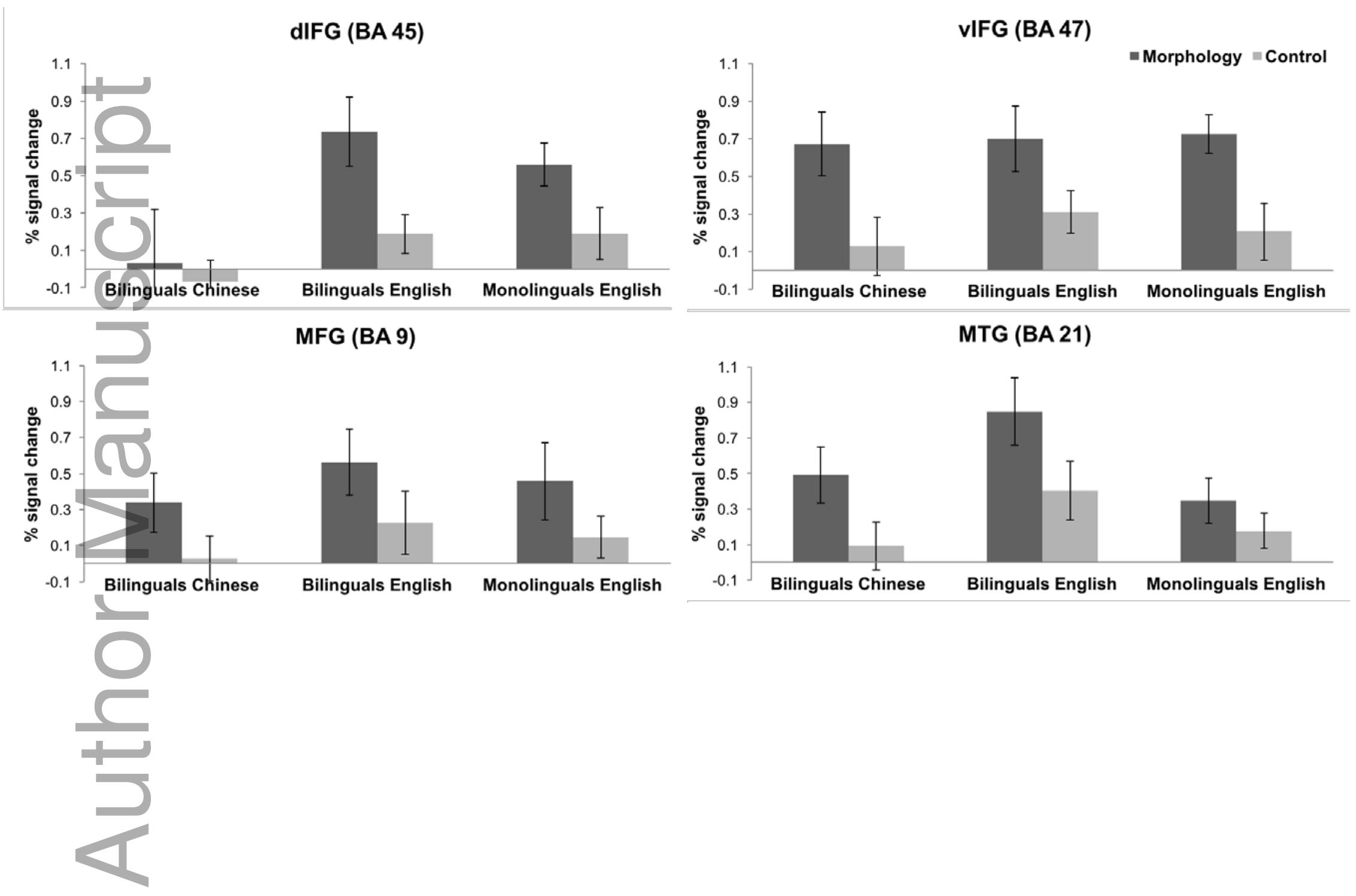

This article is protected by copyright. All rights reserved 